\title{
Aplikasi Peminjaman dan Pengembalian Koleksi Berbasis Framework Code Igniter di Perpustakaan Jurusan Teknik Sipil dan Lingkungan Fakultas Teknik UGM
}

\author{
Bagus Wijaya* \\ e-mail: bagustorono@gmail.com
}

\begin{abstract}
A library is an important facility to support the academic activities of students. There are various types of collections that require good management in order that the information retained in the collections can be utilized by the user. The collection in the library can be easily borrowed and returned quickly so as to improve the efficiency and effectiveness of the performance of library staff. The author aimed to facilitate library staff in providing collection circulation services, especially for students majoring in Civil and Environmental Engineering. The application was expected to give fast and accurate process in data as well as report collection.
\end{abstract}

Keywords: Circulation System, Framework Code Igniter, Data Processing

*) Pustakawan Fakultas Teknik UGM

\section{A. PENDAHULUAN}

1. Latar Belakang

Perpustakaan Jurusan Teknik Sipil dan Lingkungan Fakultas Teknik Univeritas Gadjah Mada (JTSL FT UGM) merupakan fasilitas penunjang kegiatan akademik mahasiswa. Beberapa jenis koleksi yang dimiliki memerlukan pengelolaan yang baik, sehingga informasi yang dimiliki dapat didayagunakan oleh pemustaka. Informasi yang dimiliki oleh perpustakaan ada yang berbentuk cetak dan file. Informasi berupa koleksi buku diupayakan dapat dengan mudah dipinjam dan dikembalikan dengan cepat sehingga dapat meningkatkan efisiensi dan efektivitas kerja pegawai perpustakaan. Dengan menggunakan aplikasi yang dibuat diharapkan dapat memberikan kemudahan bagi petugas untuk memberikan pelayanan peminjaman dan pengembalian koleksi kepada pemustaka.

\section{Rumusan Masalah}

Berdasarkan latar belakang masalah di atas dapat dirumuskan masalah yang akan dibahas dalam penelitian ini yaitu :

1. Bagaimana membuat suatu aplikasi peminjaman dan pengembalian koleksi berbasis Framework Code Igniter di Perpustakaan Jurusan Teknik Sipil dan Lingkungan Fakultas Teknik UGM?

2. Bagaimana membuat suatu aplikasi yang mudah, akurat dan tepat di dalam mengolah data koleksi di Perpustakaan Jurusan Teknik Sipil dan Lingkungan Fakultas Teknik UGM?

3. Bagaimana membuat suatu aplikasi program beserta laporan koleksi?

\section{Tujuan Penelitian}

Tujuan penelitian ini adalah:

1. Membuat suatu aplikasi peminjaman dan pengembalian koleksi berbasis Framework Code Igniter di Perpustakaan Jurusan Teknik Sipil dan Lingkungan Fakultas Teknik UGM yang cepat dan akurat.

2. Membuat suatu aplikasi yang mudah, akurat dan tepat di dalam mengolah data koleksi berbasis di Perpus-takaan Jurusan Teknik Sipil dan Lingkungan Fakultas Teknik UGM secara cepat dan akurat.

3. Membuat suatu sistem aplikasi pro-gram beserta laporan koleksi. 


\section{Manfaat Penelitian}

Sesuai dengan tujuan penelitian ini, maka manfaat yang diharapkan adalah:

1. Memperluas layanan informasi di Perpustakaan Fakultas Teknik UGM dengan memberikan layanan peminjaman dan pengembalian koleksi

2. Mempermudah proses pengolahan dan akses koleksi

3. Menghemat waktu dan tenaga untuk melakukan proses peminjaman dan pengembalian koleksi

\section{B. TINJAUAN PUSTAKA}

Endro Mustofa, (2007) menjelaskan membuat aplikasi layanan penelusuran informasi, katalog buku, input data buku, peminjaman koleksi, aplikasi ini bersifat stand alone, belum memiliki fasilitas editing informasi catalog dan belum memiliki editing daftar anggota. Dari sisi keamanan belum begitu diperhatikan dan dimungkinkan adanya celah keamanan. Sehingga dimungkinkan terjadi memanipulasi data dari pihak luar yang tidak bertanggung jawab sehingga dapat disalahgunakan.

Sedangkan Ahmad Mulyadi (2009) menyusun penelitian dengan membuat aplikasi web menggunakan file dalam penyimpanan datanya dan merupakan sistem informasi web yang tidak membutuhkan database dalam penyimpanan datanya. Aplikasi penelitian ini tidak dibuatkan pengolahan data perpustakaan seperti transaksi peminjaman dan pengembalian koleksi.

Sementara itu Deva Rizal Yahya (2010) menyusun penelitian ini dengan mengkaji dan membuat aplikasi untuk pengolahan data perpustakaan seperti: data anggota, data buku, data transaksi peminjaman dan transaksi pengembalian, denda dan informasi perpustakaan. Namun aplikasi ini belum mampu digabungkan dengan sistem barcode untuk proses peminjaman dan pengembalian koleksi.

Selanjutnya Abdul Mutaris (2011) membuat sistem informasi berbasis desktop dapat melakukan olah data denda, transaksi peminjaman, perpanjangan dan pengembalian buku, pengolahan data inventaris koleksi berupa buku serial, terbitan berkala, dan compact disc $(C D)$.

\section{Software yang Digunakan}

Sofware yang digunakan untuk membuat web penjualan pada Aplikasi Peminjaman dan Pengembalian Koleksi Berbasis Framework Code Igniter di Perpustakaan JTSL FT UGM ini adalah sebagai berikut :

1) XAMPP

Sofware ini sebenarnya sudah memuat banyak fungsi dari $M y S Q L, P H P$ dan juga Apache. Dengan menjalankan software $X A M P P$, suatu web offline sudah dapat berjalan layaknya sebuah komputer yang sudah terhubung dengan internet. Maka dengan bantuan XAMPP, suatu percobaan pembuatan dan perancangan web dapat diuji terlebih dahulu secara off-line. Namun adakalanya juga, software ini susah di peroleh, jadi di samping XAMPP juga perlu mengetahui software lain yang dapat menjalankan web secara off-line, seperti yang akan disebutkan dibawah ini.

2) MySQL

MySQL adalah salah satu aplikasi database server yang sangat terkenal hari ini. Untuk kebutuhan seorang programmer, $M y S Q L$ sudah dapat diandalkan. Selain gratis juga sangat reliable. MySQL sebetulnya lebih dikenal di dunia programming web, karena biasanya jika menggunakan CMS (Content Management System) sudah hampir dipastikan pasti berhubungan dengan MySQL. Bahkan konon, MySQL pun dipakai oleh Yahoo Finance dan tentu hal itu bisa sedikit menenangkan programmer karena sudah terbukti ketahanannya.

3) PHP

PHP memiliki kemampuan untuk membuat website menjadi dinamis atau dengan kata lain dapat berinteraksi dengan pengunjung website. Contoh paling gampang adalah shopping cart yang dimiliki oleh kebanyakan website yang menjual barang atau biasa disebut dengan e-commerce.

\section{Pengenalan Framework}

Framework adalah kumpulan perintah atau fungsi dasar yang membentuk aturan-aturan tertentu dan saling berinteraksi satu sama lain sehingga dalam pembuatan aplikasi website harus mengikuti aturan dari framework 
tersebut. Framework tidak perlu memikirkan kode perintah/ fungsi dasar dari aplikasi website.

Keuntungan pembuatan web menggunakan framework:

1. Waktu pembuatan aplikasi website jauh lebih singkat

2. Kode aplikasi website menjadi lebih mudah dibaca

3. Website jadi lebih mudah diperbaiki

4. Tidak perlu lagi membuat kode penunjang aplikasi web seperti koneksi database, validasi form, GUI (Graphical User Interface) dan keamanan.

\section{Code Igniter}

Code igniter adalah salah satu framework yang akan digunakan untuk membuat aplikasi peminjaman dan pengembalian koleksi berbasis Framework Code Igniter di Perpustakaan Jurusan Teknik Sipil Fakultas Teknik UGM. Adapun beberapa keuntungan menggunakan framework Code igniter adalah:

1. Gratis

2. Ditulis menggunakan $P H P 4$

3. Berukuran kecil

4. Menggunakan konsep $M-V-C$ (Model, View and Controller)

5. URL (Uniform Resource Locator) yang sederhana

6. Memiliki paket library yang lengkap

7. Tidak memerlukan Template Engine

8. Dokumetasi lengkap dan jelas

\section{HASIL DAN PEMBAHASAN}

Merancang database merupakan hal yang sangat penting. Kesulitan utama dalam merancang database yakni bagaimana memuaskan keperluan pemustaka saat ini dan yang akan datang. Perancangan model konseptual perlu dilakukan disamping perancangan fisik. Pada perancangan konseptual akan menunjukkan entity dan relasinya berdasarkan proses yang diinginkan oleh organisasi. Ketika menentukan entity dan relasi dibutuhkan analisis data tentang informasi.

\section{Desain Basis Data}

\section{a. Proses Normalisasi}

Bentuk tidak normal merupakan kumpulan data yang direkam, tidak ada keharusan mengikuti suatu format tertentu, dimungkinkan data tidak lengkap atau terduplikasi. Data dikumpulkan apa adanya sesuai dengan kedatangannya.

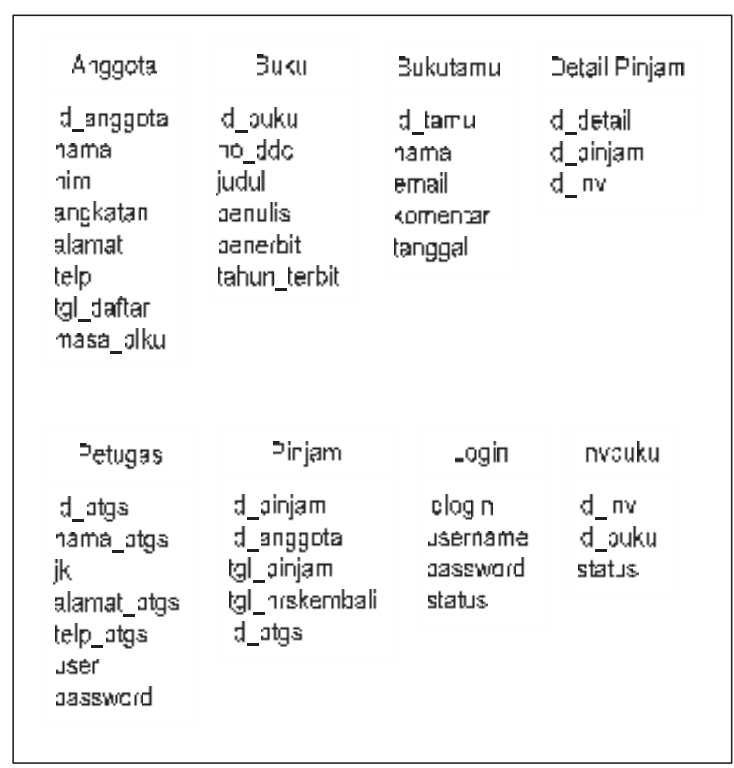

Gambar 1. Bentuk Tidak Normal

\section{b. Relasi Antar Tabel}

Untuk menjadi bentuk relasi antar tabel haruslah dalam bentuk normal ketiga.

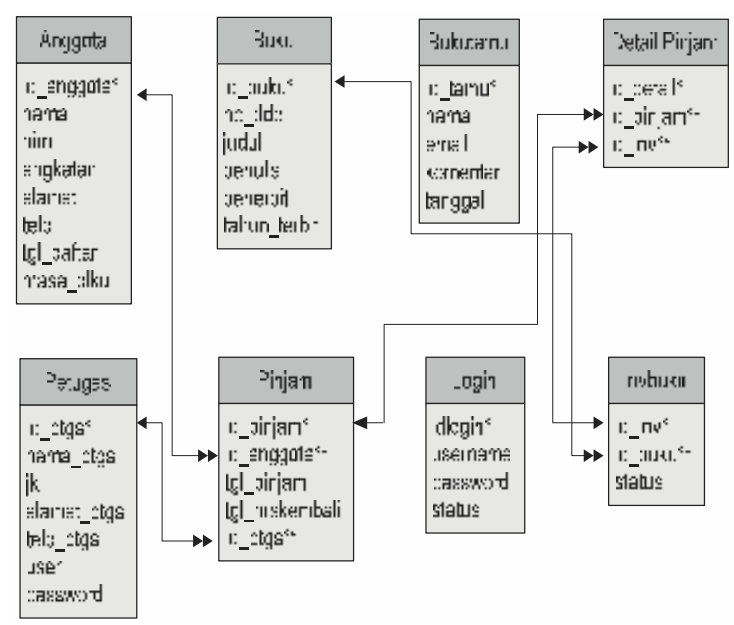

Gambar 2 . Relasi Antar Tabel

Keterangan :

* : Kunci Primer

** : Kunci Tamu 


\section{c. Kamus Data Tabel}

1) Tabel Buku

Nama Tabel : Buku

Kunci Tabel : ID Buku

Tipe File : File Master

Kegunaan : Menyimpan data inventaris Tabel 1. Tabel Buku

\begin{tabular}{cllcl}
\hline No & Nama Field & Tipe & Lebar & Keterangan \\
\hline 1 & ID_Buku & Integer & 20 & ID Buku \\
2 & No_DDC & Varchar & 20 & Nomor Klasifikasi \\
& & & & Buku \\
3 & Judul & Varchar & 80 & Judul Koleksi \\
4 & Penulis & Varchar & 30 & Nama Penulis \\
5 & Penerbit & Varchar & 20 & Penerbit \\
6 & Tahun Terbit & Year & 4 & Tahun Terbit \\
\hline
\end{tabular}

2) Tabel Login

Nama Tabel : Login

Kunci Tabel : ID Login

Tipe File : File Master

Kegunaan : Menyimpan data login

\begin{tabular}{cllcl}
\multicolumn{5}{c}{ Tabel 2. Tabel Login } \\
\hline No & Nama Field & Tipe & Lebar & Keterangan \\
\hline 1 & ID_Login & Integer & 10 & ID Login \\
2 & Username & Varchar & 100 & Username \\
3 & Password & Varchar & 100 & Password \\
4 & Status & Integer & 5 & Status Login \\
5 & Id_ptgs & Integer & 11 & ID Petugas \\
\hline
\end{tabular}

3) Tabel Anggota

Nama Tabel : Anggota

Kunci Tabel : ID_Anggota

Tipe File : File Master

Kegunaan : Menyimpan data anggota

Tabel 3. Tabel Anggota

\begin{tabular}{|c|c|c|c|c|}
\hline No & Nama Field & Tipe & Lebar & Keterangan \\
\hline 1 & ID_Anggota & Varchar & 15 & $\begin{array}{l}\text { Nomor id } \\
\text { anggota }\end{array}$ \\
\hline 2 & Nama & Varchar & 30 & Jenis koleksi \\
\hline 3 & Nim & Varchar & 10 & $\begin{array}{l}\text { Nomor induk } \\
\text { mahasiswa }\end{array}$ \\
\hline 4 & Angkatan & Varchar & 10 & $\begin{array}{l}\text { Tahun masuk } \\
\text { mahasiswa }\end{array}$ \\
\hline 5 & JK & Enum & & $\begin{array}{l}\text { Jenis kelamin } \\
\text { anggota }\end{array}$ \\
\hline 6 & Alamat & Varchar & 50 & $\begin{array}{l}\text { Alamat } \\
\text { anggota }\end{array}$ \\
\hline 7 & Telp & Varchar & 15 & $\begin{array}{l}\text { Nomor } \\
\text { telepon } \\
\text { anggota }\end{array}$ \\
\hline 8 & Tgl_daftar & Date & & $\begin{array}{l}\text { Tanggal } \\
\text { pendaftaran } \\
\text { anggota }\end{array}$ \\
\hline 9 & Masa_blku & Date & & $\begin{array}{l}\text { Masa berlaku } \\
\text { anggota }\end{array}$ \\
\hline
\end{tabular}

4) Tabel Buku Tamu

Nama Tabel : Buku Tamu

Kunci Tabel : ID Buku Tamu

Tipe File : File Master

Kegunaan : Menyimpan data buku tamu

Tabel 4. Tabel Buku Tamu

\begin{tabular}{|c|c|c|c|c|}
\hline No & Nama Field & Tipe & Lebar & Keterangan \\
\hline 1 & $\begin{array}{l}\text { ID_Buku } \\
\text { Tamu }\end{array}$ & Integer & 10 & $\begin{array}{l}\text { Nomor id buku } \\
\text { tamu }\end{array}$ \\
\hline 2 & Nama & Varchar & 80 & Jenis pengguna \\
\hline 3 & Email & Varchar & 80 & $\begin{array}{l}\text { Email } \\
\text { pengguna }\end{array}$ \\
\hline 4 & Komentar & Text & - & $\begin{array}{l}\text { Komentar } \\
\text { pengguna }\end{array}$ \\
\hline 5 & Tanggal & Date & - & $\begin{array}{l}\text { Tanggal } \\
\text { memasukkan } \\
\text { komentar }\end{array}$ \\
\hline
\end{tabular}

5) Tabel Detail Pinjam

Nama Tabel : Detail Pinjam

Kunci Tabel : ID Detail

Tipe File : File Master

Kegunaan : Menyimpan data detail pinjam

Tabel 5. Tabel Detail Pinjam

\begin{tabular}{|c|c|c|c|c|}
\hline No & Nama Field & Tipe & Lebar & Keterangan \\
\hline 1 & ID_Detail & Integer & 11 & $\begin{array}{l}\text { Nomor id } \\
\text { detail pinjam }\end{array}$ \\
\hline 2 & ID_Pinjam & Integer & 10 & $\begin{array}{l}\text { Nomor id } \\
\text { pinjam }\end{array}$ \\
\hline 3 & ID_Inv & Varchar & 20 & $\begin{array}{l}\text { Nomor id } \\
\text { inventaris }\end{array}$ \\
\hline 4 & Status & Tinyint & 1 & $\begin{array}{l}\text { Status detail } \\
\text { pinjam }\end{array}$ \\
\hline
\end{tabular}

6) Tabel Invbuku

Nama Tabel : Invbuku

Kunci Tabel : ID Inv

Tipe File : File Master

Kegunaan : Menyimpan data inventaris buku

Tabel 6. Tabel Invbuku

\begin{tabular}{|c|c|c|c|c|}
\hline No & $\begin{array}{l}\text { Nama } \\
\text { Field }\end{array}$ & Tipe & Lebar & Keterangan \\
\hline 1 & ID_Inv & Varchar & 20 & $\begin{array}{l}\text { Nomor id } \\
\text { inventaris buku }\end{array}$ \\
\hline 2 & Id_Buku & Varchar & 20 & Nomor id buku \\
\hline 3 & Status & Enum & & $\begin{array}{l}\text { Status } \\
\text { peminjaman } \\
\text { buku }\end{array}$ \\
\hline
\end{tabular}


7) Tabel Petugas

Nama Tabel : Petugas

Kunci Tabel : ID Buku Tamu

Tipe File : File Master

Kegunaan : Menyimpan data buku tamu

Tabel 7. Tabel Petugas

\begin{tabular}{|c|c|c|c|c|}
\hline No & Nama Field & Tipe & Lebar & Keterangan \\
\hline 1 & ID_Petugas & Integer & 10 & $\begin{array}{l}\text { Nomor id } \\
\text { petugas }\end{array}$ \\
\hline 2 & Nama_ptgs & Varchar & 30 & Nama petugas \\
\hline 3 & $\mathrm{Jk}$ & Enum & & $\begin{array}{l}\text { Jenis kelamin } \\
\text { petugas }\end{array}$ \\
\hline 4 & Alamat_ptgs & Varchar & 50 & $\begin{array}{l}\text { Alamat } \\
\text { petugas }\end{array}$ \\
\hline 5 & Telp_ptgs & Varchar & 13 & $\begin{array}{l}\text { Nomor telepon } \\
\text { petugas }\end{array}$ \\
\hline 6 & Username & Varchar & 15 & $\begin{array}{l}\text { Username } \\
\text { petugas }\end{array}$ \\
\hline 7 & Password & Varchar & 50 & $\begin{array}{l}\text { Password } \\
\text { petugas }\end{array}$ \\
\hline 8 & Status & Tinyint & 1 & Status petugas \\
\hline
\end{tabular}

8) Tabel Pinjam

Nama Tabel : Pinjam

Kunci Tabel: ID Buku Tamu

Tipe File : File Master

Kegunaan : Menyimpan data buku tamu

Tabel 8. Tabel Pinjam

\begin{tabular}{cllcl}
\hline No & Nama Field & Tipe & Lebar & Keterangan \\
\hline 1 & ID_Pinjam & Integer & 10 & $\begin{array}{l}\text { Nomor id } \\
\text { pinjam }\end{array}$ \\
2 & ID_Anggota & Varchar & 15 & $\begin{array}{l}\text { Nomor id } \\
\text { anggota }\end{array}$ \\
3 & Tgl_pinjam & Date & & $\begin{array}{l}\text { Tanggal } \\
\text { pinjam }\end{array}$ \\
4 & Tgl_hrskembali & Date & & $\begin{array}{l}\text { Tanggal } \\
\text { pengembalian }\end{array}$ \\
5 & Id_Petugas & Varchar & 10 & $\begin{array}{l}\text { Nomor id } \\
\text { petugas }\end{array}$ \\
6 & Status & Tinyint & 1 & Status \\
\hline
\end{tabular}

\section{d. Flowchart Program Halaman Utama}

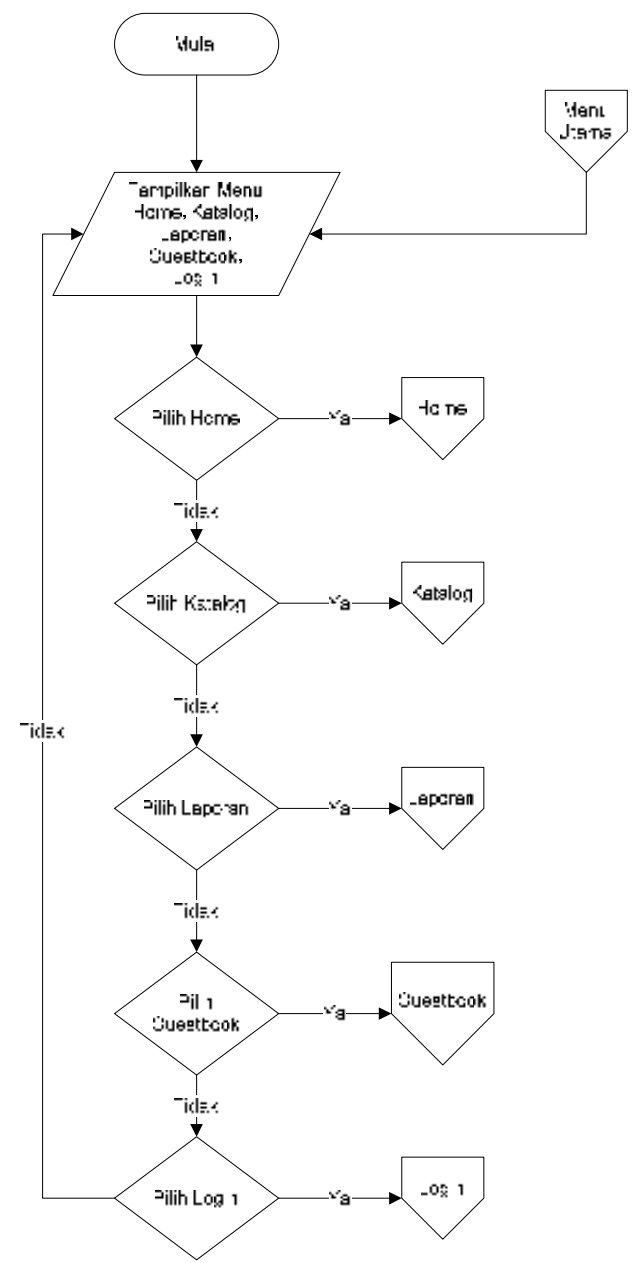

Gambar 3. Flowchart Program Halaman Utama 


\section{e. Flowchart Program Halaman Administrator}

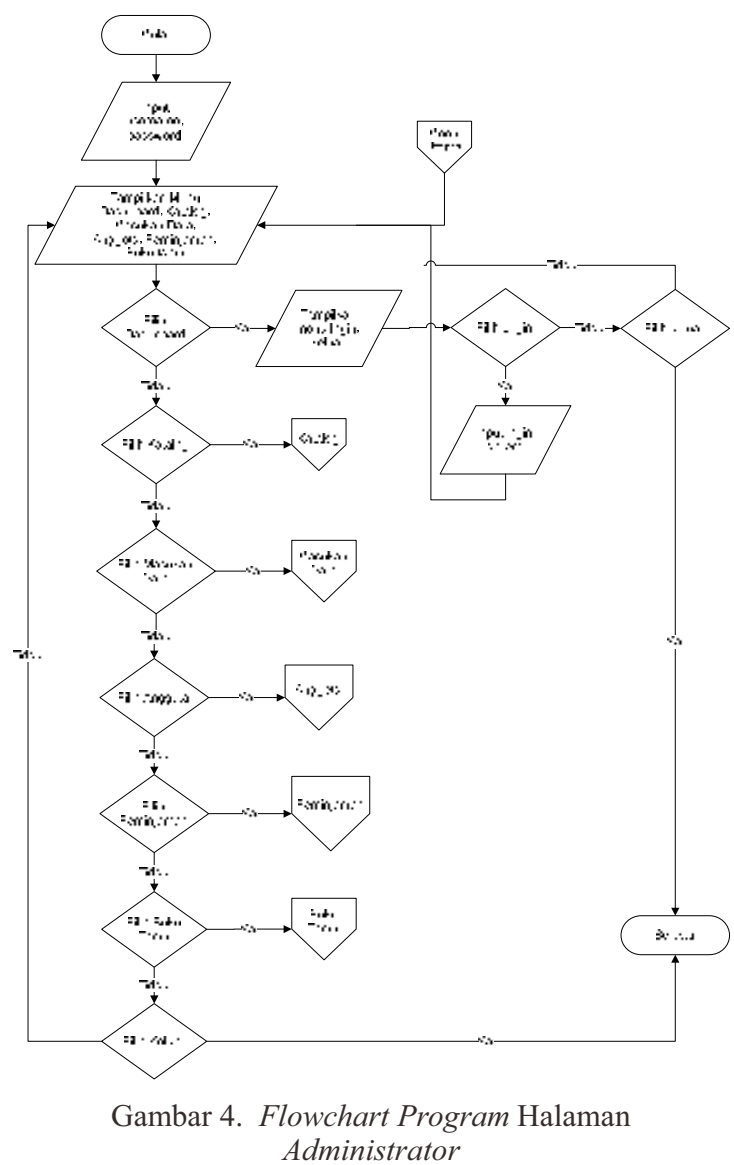

\section{f. Flowchart Program Transaksi}

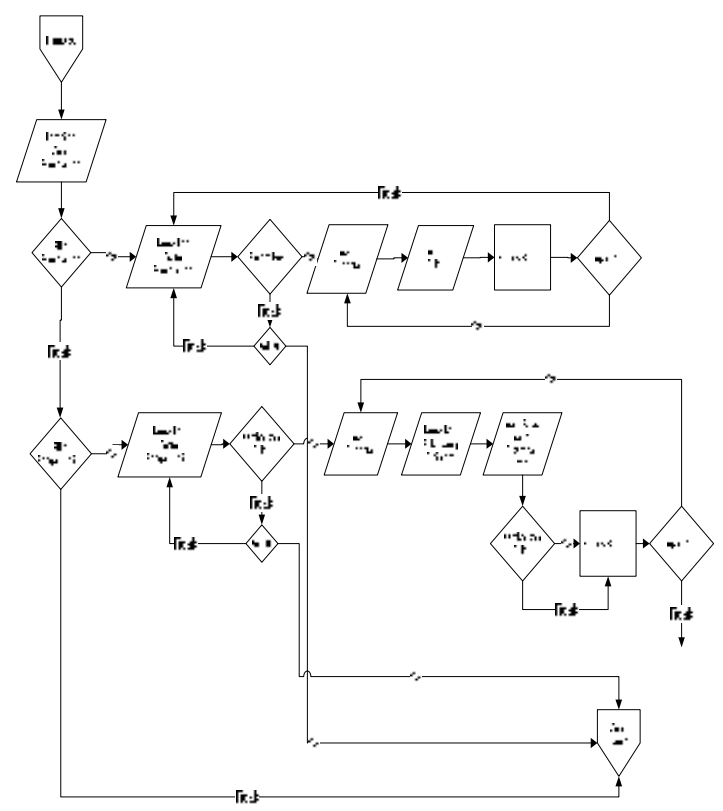

Gambar 5. Flowchart Program Transaksi

\section{KESIMPULAN}

Aplikasi peminjaman dan pengembalian koleksi berbasis Framework Code Igniter di Perpustakaan Jurusan Teknik Sipil dan Lingkungan Fakultas Teknik UGM dapat melakukan proses peminjaman dan pengembalian, mengolah data koleksi dan membuat laporan koleksi yang cepat dan akurat.

Untuk itu aplikasi ini perlu dikembangkan menjadi aplikasi yang lebih memudahkan pemustaka dalam melakukan proses perhitungan secara otomatisasi. Oleh karena itu, disarankan agar aplikasi ini dapat dikembangkan menjadi suatu aplikasi yang lebih lengkap dan mempunyai fungsi yang optimal bagi pemustaka.

\section{DAFTAR PUSTAKA}

Mutaris, Abdul. 2011. Sistem Informasi Perpustakaan SMAN 1 Piyungan. Yogyakarta. Yogyakarta: STMIK El Rahma

Kadir, A. 2003, Dasar Pemrograman Web Dinamis Menggunakan PHP, Penerbit : Andi, Yogyakarta

Kadir, A. 2003, Konsep \& Tuntunan Praktis Basis Data. Penerbit: Andi, Yogyakarta.

Mulyadi, Ahmad. 2009. Aplikasi Web Perpustakaan Online Berbasis File Menggunakan PHP. Yogyakarta : STMIK El Rahma.

Yahya, Deva Rizal. 2010. Sistem Informasi Perpustakaan SMA Muhammadiyah 3 Yogyakarta Berbasis SMS Gateway. Yogyakarta: STMIK El Rahma.

Hakim, L. 2010, Membangun Web Berbasis PHP dengan Framework Codeigniter, Yogyakarta, Lokomedia.

Kristianto, H. 1994, Konsep dan Perancangan Database, Yogyakarta:Andi

Mustofa, Endro. 2007. Komputerisasi Informasi Koleksi Buku-Buku Perpustakaan. Yogyakarta : STMIK El Rahma.

Sidik, B. 2006, Pemrograman Web dengan PHP, Bandung: Informatika.

Wahana Komputer. 2005, Membuat Program Kreatif dan Profesional. Jakarta: Gramedia. 